\title{
FORMAÇÃO CONTINUADA PARA A ETAPA DA EDUCAÇÃO INFANTIL: CAMINHOS DE REFLEXÕES E SABERES
}

\author{
Continuous formation for childhood education: ways of reflection and knowledge \\ Formación continuada para la etapa de la educación infantil: caminos de reflexión \\ y saberes
}

\author{
Roseli Maria Rosa de Almeida* \\ Felipe Silva Vedovoto*
}

\begin{abstract}
Resumo
Os avanços científicos, históricos e culturais passaram a considerar a criança como sujeito que tem sua própria singularidade. Isso trouxe novas configurações do brincar como ferramenta essencial para o desenvolvimento infantil. Para refletir sobre esses aspectos, o projeto de extensão universitária "Jogos, Brinquedos e Brincadeiras: a infância e sua singularidade", desenvolvido na UFMS/Campus de Naviraí/MS, no período de junho a novembro de 2019, com carga horária de 40 horas para o público participante, inclui palestras, exposições de jogos, brinquedos, brincadeiras e oficinas de produção de materiais. O público-alvo é composto de professores/as da educação infantil, coordenadores/as e acadêmicos/as do Curso de Pedagogia. O objetivo geral do trabalho é o de implementar ações de formação de professores da etapa da educação infantil visando discutir, selecionar e produzir recursos pedagógicos que darão suporte à ação educativa em Centros Integrados de Educação Infantil de Naviraí/MS. Espera-se, com os objetivos específicos: a) discutir pesquisas sobre o brincar na educação infantil; b) analisar jogos, brinquedos, brincadeiras e as estratégias metodológicas para o trabalho com esses suportes na educação infantil; e c) produzir materiais para o uso em instituições de educação infantil.
\end{abstract}

PALAVRAS-CHAVE: Formação continuada. Educação Infantil. Ludicidade.

\begin{abstract}
Scientific, historical and cultural advances have considered a child as an individual who presents his or her own singularity. This has brought new configurations of playing as an essential tool for the childhood development. In order to reflect about these aspects, there is a university project named "Games, Toys and Kids Plays: the childhood and its singularity", which was developed at UFMS/Navirai Campus-MS, between June to November 2019, offered in a 40-hour-course for adults including lectures, plays, games exhibitions, toys, children plays and workshops for producing educational materials. The target public are teachers, coordinators and undergraduate students from Pedagogy Course. The general aim from this work is to implement actions for teachers from childhood education by talking and discussing, selecting

\footnotetext{
* Docente na Universidade Federal de Mato Grosso do Sul (UFMS/Campus de Naviraí). Coordenadora do projeto de Extensão "Jogos, brinquedos e brincadeiras: a infância e sua singularidade". Email: roselimariarosa@yahoo.com.br

* Mestre em Ensino de História pela Universidade Estadual em Mato Grosso do Sul (UEMS). Técnico de Laboratório de Ensino do Campus de Naviraí da Universidade Federal de Mato Grosso do Sul (UFMS/Campus de Naviraí), participante do Projeto de Extensão "Jogos, brinquedos e brincadeiras: a infância e sua singularidade”. E-mail: felipe.vedovoto@ufms.br
} 
and producing pedagogical resources to support educational actions at Integrated Centers of Childhood Education in the city of Navirai, MS. By taking the specific objectives, it is expected to: a) debate researches about "playing" at childhood education; b) analyze games, toys, plays and methodological strategies for working with these tools at childhood education; and c) produce material for using in childhood education institutions.

KEYWORDS: Continuous Formation. Childhood Education. Playfulness.

\section{Resumen}

Los avanzos científicos, históricos y culturales pasaron a considerar el niño como sujeto que tiene su própria singularidad. Eso trajo nuevas configuraciones del jugar como herramienta esencial para el desarrollo infantil. Para refletir sobre esos aspectos, el proyecto de extensión universitária "Juegos, Juguetes y Jugueteos: la infancia y su singularidad", desarrollado en UFMS/Campus de Naviraí/MS, en el período de junio a noviembre de 2019, con carga horaria de 40 horas para el publico participante, incluye conferencias, exposiciones de juegos, juguetes, jugueteos y taller de producción de materiales. El publico meta es compuesto de profesores/as de la educación infantil, coodinadores/as y académicos/as del Curso de Pedagogía. El objetivo general del trabajo es implementar acciones de formación de profesores de la etapa de la educación infantil visando discutir, seleccionar y producir recursos pedagógicos que darán suporte para la acción educativa en Centros Integrados de Educación Infantil de Naviraí/MS. Se espera, con los objetivos específicos: a) discutir pesquisas sobre el jugar en la educación infantil; b) analizar juegos, juguetes, jugueteos y estratégias metodológicas para el trabajo con esos suportes en la educación infantil; y c) producir materiales para el uso en intituiciones de educación infantil.

PALABRAS CLAVE: Formación continuada. Educación infantil. Ludicidad.

\section{INTRODUÇÃO}

O texto em questão apresenta o projeto de extensão universitária "Jogos, Brinquedos e Brincadeiras: a infância e sua singularidade", em andamento na Universidade Federal de Mato Grosso do Sul/Campus de Naviraí - UFMS/CPNV. O município de Naviraí está localizado no sul da região Centro-Oeste do Brasil, no sudoeste do Estado de Mato Grosso do Sul. Possui uma área territorial de 3.193,541 $\mathrm{km}^{2}$ e uma população de 52.367 habitantes (IBGE, 2016). O município se localiza na microrregião de Iguatemi/MS e os seus habitantes se identificam pelo gentílico "naviraiense".

No tocante à educação infantil, o município atende crianças de 0 a 5 anos de idade em seis Centros Integrados de Educação Infantil - CIEIs com duas extensões. Há também duas escolas de ensino fundamental com cinco turmas de pré-escola (faixa etária de 4 a 5 anos) em cada uma delas. Conforme informações da Gerência Municipal de Educação, no ano de 2019 há um total de 200 professores/as da educação infantil na rede municipal de educação, considerando efetivos e contratados, que, portanto, atuam em CIEIs de Naviraí/MS.

Quanto à formação docente continuada para esses professores da educação infantil, ela foi organizada por meio de projeto de extensão universitária e o objetivo, além de implementar ações de formação de professores da etapa da educação infantil, inclui também discutir, selecionar e produzir recursos pedagógicos (jogos, brinquedos e brincadeiras) que darão suporte à ação educativa em CIEIs de Naviraí/MS. Assim, os 
objetivos específicos almejam: i) avaliar e discutir pesquisas sobre o brincar na educação infantil; ii) analisar materiais produzidos (jogos, brinquedos, brincadeiras) e as estratégias metodológicas para o trabalho com esses suportes na educação infantil; e iii) produzir jogos, brinquedos e brincadeiras para o uso em instituições de educação infantil.

O Campus da Universidade Federal do Mato Grosso do Sul em Naviraí iniciou as suas atividades no ano de 2009 com os Cursos de Pedagogia e de Ciências Sociais licenciaturas - e desde sua inauguração desenvolveu projetos de extensão em parceria com a Gerência Municipal de Educação de Naviraí, incluindo escolas estaduais e municipais. A formação de professores esteve presente em vários projetos de extensão e pesquisa desenvolvidos com a educação básica. A equipe que propõe o projeto de extensão atua com essa questão há alguns anos, na realização, desde 2012, da Feira de Jogos, Brinquedos e Brincadeiras do Campus de Naviraí, como parte das atividades da disciplina Ludicidade e Educação, além de outros projetos de formação de professores da educação infantil desenvolvidos pelas docentes da UFMS em parceria com outras instituições.

Dessa forma, destaca-se a relevância do trabalho de formação com os professores da educação infantil. A ação proposta articula o ensino, pesquisa e extensão universitária. Quanto ao ensino, a articulação contempla discussão teórica sobre o brincar e a elaboração de materiais nas disciplinas de Ludicidade e Educação e de Fundamentos e Metodologias da Educação Infantil, ofertadas aos acadêmicos do Curso de Pedagogia da UFMS/CPNV. No caso da pesquisa, ela ocorre por meio do levantamento dos trabalhos desenvolvidos sobre a temática e discussão com professores/as e acadêmicos/as, em palestras e oficinas. Por fim, a extensão universitária é realizada por meio do atendimento da demanda de formação apresentada pela rede municipal de ensino em relação aos professores da educação infantil e isso é feito nos diversos eixos constantes das Diretrizes Curriculares Nacionais para a Educação Infantil, ao considerar que "[...] as práticas pedagógicas que compõem a proposta curricular da educação infantil devem ter como eixos norteadores as interações e a brincadeira" (BRASIL, 2010, p. 25).

A ação extensionista propõe-se a cumprir a sua função ao integrar professores/as, acadêmicos/as e pesquisadores/as da temática, em estudos, discussões e oficinas, socializando, dessa maneira, a produção de conhecimentos na área.

\section{A importância dos jogos, brinquedos e brincadeiras para a/s infância/s}

Destacamos que as pesquisas sobre os jogos, brinquedos e brincadeiras e a educação (KISHIMOTO, 2011; RIBEIRO, 2011) nos mostram que historicamente houve alterações e permanências em relação a jogos, brinquedos e brincadeiras no tocante a concepções, importância, formatos, usos e relevância, em diversos contextos sociais e, consequentemente, na educação. Na questão da análise dos aspectos lúdicos na educação, podemos afirmar que houve o desenvolvimento de estudos históricos, psicológicos e pedagógicos. Assim, a mudança no conceito de infância e os avanços científicos, históricos e culturais passaram a considerar a criança como sujeito que tem sua própria singularidade e o brincar passou a ser considerado ferramenta essencial para o desenvolvimento infantil.

As Diretrizes Curriculares Nacionais da Educação Infantil (BRASIL, 2010) definem criança como "[...] sujeito histórico e de direitos que, nas interações, relações e práticas cotidianas que vivencia, constrói sua identidade pessoal e coletiva, brinca, 
imagina, fantasia, deseja, aprende, observa, experimenta, narra, questiona e constrói sentidos [...]" (p. 12). Consideramos, dessa maneira, a/s infância/s como importantes etapas das vidas humanas, em que o brincar se torna elemento efetivo na constituição da personalidade infantil, pois a/s criança/s se situa/m em um contexto histórico e social, ou seja, em um ambiente com valores, significados, atividades e artefatos construídos e partilhados pelos sujeitos que ali vivem. Ela/s incorpora/m, dessa maneira, a experiência social e cultural do brincar por meio das relações que estabelece $/ \mathrm{m}$ com os outros (BORBA, 2007) e, além disso, produz/em cultura/s.

Dito isto e apesar de todos os avanços científicos e benefícios cognitivos, sociais e emocionais atribuídos à tríade jogo/brinquedo/brincadeira para a criança, Borba (2007) nos alerta para o fato de que, nas sociedades ocidentais, essa atividade ainda é considerada irrelevante ou de pouco valor do ponto de vista da educação formal, assumindo um significado de oposição ao trabalho, tanto no contexto da escola quanto no cotidiano familiar. Dessa maneira, torna-se relevante o estudo e discussões sobre a temática em seus aspectos teórico-metodológicos, especialmente com profissionais (professores e coordenadores) dos CIEIs de Naviraí, espaços esses de educação e de cuidado das crianças de 0 a 5 anos.

Nem sempre a atuação com a criança em instituições de educação infantil enfatiza a necessidade de um trabalho estruturado com o brincar, bem como o planejamento como forma de minimizar o espontaneísmo pedagógico ou mesmo o excesso de direcionamento na atividade com a criança. As dificuldades para desenvolver um trabalho permeado pelo aspecto lúdico vão desde as questões da organização do espaço físico, a formação dos professores, as concepções da instituição e até mesmo a ausência e/ou deficiência de materiais lúdicos.

As Diretrizes Curriculares Nacionais da Educação Infantil (BRASIL, 2010) preveem, como princípios estéticos das propostas de trabalho com as crianças da educação infantil: a sensibilidade, a criatividade, a ludicidade e a liberdade de expressão nas diferentes manifestações artísticas e culturais. A ludicidade aparece como um dos pilares dos princípios estéticos no trabalho com as crianças da educação infantil. Além disso, o currículo nas DCNEI (BRASIL, 2010) é definido como um "[...] conjunto de práticas que buscam articular as experiências e os saberes das crianças com os conhecimentos que fazem parte do patrimônio cultural, artístico, ambiental, científico e tecnológico [...]" (p. 12).

Essas práticas precisam estar articuladas à educação, ao cuidado e ao brincar, que são os eixos integradores da formação da criança. A formação de professores tornase, assim, espaço propício para a socialização das pesquisas, para a discussão da prática pedagógica e para a articulação entre universidade e comunidade.

\section{Teorias, concepções e práticas pedagógicas do brincar}

O desenvolvimento de pesquisas teórico-metodológicas em relação aos jogos, brinquedos e brincadeiras e sua relação com a educação das crianças (KISHIMOTO, 2000, 2010; 2011; BORBA, 2007) aponta que o brincar para a criança é a atividade principal do dia a dia. É no contexto das brincadeiras que as crianças elaboram e exercitam o poder de tomar decisões, expressar sentimentos e valores, conhecer a si mesmas, aos outros e ao mundo, de repetir ações prazerosas, de partilhar, de expressarse por meio de diferentes linguagens, de usar o corpo, os sentidos, os movimentos, de solucionar problemas e criar. 
Segundo Borba (2007), “[...] a experiência do brincar cruza diferentes tempos e lugares, passados, presentes e futuros, sendo marcada ao mesmo tempo pela continuidade e pela mudança" (p. 33). Na brincadeira, a criança experimenta o poder de explorar o mundo dos objetos, das pessoas, da natureza e da cultura. Além disso, no plano da imaginação, o brincar se sobressai pela mobilização dos significados/sentidos. Dessa maneira, a relevância do brincar se pauta na cultura da infância, que a coloca como ferramenta efetiva para que a criança se expresse, aprenda e se desenvolva.

Segundo Kishimoto (2010), a criança não nasce sabendo brincar. Ela precisa aprender a brincar e ela aprende a brincar por meio das interações com outras crianças e com os adultos. Assim, ela descobre, em contato com objetos e brinquedos, certos modos de uso desses materiais. Além disso, observando outras crianças e as intervenções da professora, a criança aprende novas brincadeiras e suas regras.

A partir dessas considerações, descreveremos alguns conceitos que foram atribuídos aos jogos, aos brinquedos e às brincadeiras por pesquisadores da temática. Segundo Kishimoto (2011), há uma dificuldade para conceituar a palavra "jogo", especialmente pelos significados atribuídos ao termo em cada cultura. Desse modo aponta três questões que podem auxiliar na definição de jogo, que são características estudadas por pesquisadores como Gilles Brougère e Jacques Henriot. Kishimoto (2011) preconiza que, acompanhando o entendimento desses autores, haveremos que observar a presença de três caraterísticas para considerarmos que estamos falando de "jogo": i) o resultado de um sistema linguístico que funciona dentro de um contexto social, ii) um sistema de regras e iii) um objeto. Esses três aspectos, articulados, definem o que é o jogo.

Com relação ao brinquedo, Kishimoto (2011) atesta que este é o objeto, o suporte da brincadeira e, além disso, pressupõe uma relação intima com a criança, com seu nível de desenvolvimento e a indeterminação quanto ao seu uso, ou seja, um cabo de vassoura pode ser "um cavalinho", pois o objeto evoca um simbolismo, em que a criança representa, por meio de suas ações, o seu cotidiano, a sua realidade. O que seria então a brincadeira? É definida por Kishimoto (2011) como a ação que a criança desempenha ao mergulhar na atividade lúdica.

Compete-nos enfatizar que as atividades lúdicas nos contextos das instituições de educação infantil são ferramentas essenciais ao desenvolvimento infantil. Quanto a isso, no entanto, Kishimoto (2011) nos alerta para um problema que se deu ao longo da implantação das creches e das pré-escolas no país, especialmente a partir dos anos de 1970, o de favorecer o dito "brincar livre". O brincar "livre" foi caraterizado por espaços quase vazios de brinquedos, com poucos ou até mesmo sucateados e/ou inadequados materiais, o que não favoreceu um trabalho estruturado com o brincar. Os materiais raras vezes atendiam às crianças, o que favorecia correria e empurrões, de forma que não se concretizava uma forma adequada de trabalho educacional.

Em pesquisa realizada por Kishimoto (2000) fica evidenciada a necessidade de repensar as questões que envolvem o brincar na educação infantil, pois, embora as Diretrizes Curriculares Nacionais para a Educação Infantil (DCNEI, 2010) apontem a necessidade do desenvolvimento da criança e da sua autonomia, tais concepções não se materializam no espaço físico e nas práticas pedagógicas das instituições. Ocorre que, muitas vezes, a organização física da sala não propicia o uso independente dos materiais e as atividades realizadas pelas crianças são sempre dirigidas e cronometradas pelo professor. Então é uma visão adultocêntrica que predomina.

A pesquisadora Kishimoto (2000) destaca ainda que é comum, no chamado "Dia do Brinquedo", a professora separar os brinquedos pelo critério do sexo e deixar para as 
meninas as bonecas, cestinhas, ferros de passar, pratos, xícaras, telefones e, para os meninos, carrinhos, instrumentos musicais, super-heróis, cavalos de madeira, chegando a reprimir os meninos quando pegam brinquedos da caixa das meninas. Isso mostra que é necessário haver uma reflexão sobre as práticas relacionadas à igualdade de gêneros no tocante ao brincar. Na mesma pesquisa, Kishimoto (2000) afirma que há um "[...] brincar interditado em sala de aula" (p. 11), o que, para a pesquisadora, "[...] faz emergir, muitas vezes, fugas em busca das representações simbólicas e de momentos de interação entre pares, sistematicamente reprimidas" (p. 11).

Há de se considerar ainda a estrutura pedagógica e as concepções da instituição acerca do brincar, pois a pesquisa de Kishimoto (2000), em instituições de educação infantil do estado de São Paulo, mostrou que o brincar requer a autonomia da criança para explorar seu espaço de brincadeira, escolher seus parceiros e os objetos utilizados no contexto lúdico, mas, se tais condições não estão presentes, não se pode garantir um ambiente educativo que incorpore o lúdico. No entendimento de Kishimoto (2000), ainda que as instituições se esforcem para desenvolver atividades e oficinas em que o brincar e a autonomia estejam presentes, tais atividades são ocasionais e não fazem parte da rotina escolar, não são algo permanente no cotidiano das crianças e isso dificulta a construção de uma cultura lúdica no espaço das instituições de educação infantil.

Assim, a formação docente continuada dos profissionais que atuam com as crianças de 0 a 5 anos se faz necessária, para uma discussão e aprofundamento das questões que envolvem o brincar como parte integrante, componente essencial do desenvolvimento do currículo das instituições de educação infantil.

\section{Metodologia e avaliação do trabalho de extensão universitária}

A metodologia do projeto de extensão universitária em questão é desenvolvida de forma a alcançar os objetivos propostos ao longo dos 6 meses de trabalho (junho a novembro de 2019). As etapas foram organizadas da seguinte maneira: i) a primeira etapa consistiu nas inscrições de professores dos Centros Integrados de Educação Infantil - CIEIs; ii) na segunda etapa os professores dos CIEIs participaram de uma palestra inicial do projeto e fizeram a visitação à Feira de Jogos, Brinquedos e Brincadeiras promovida pelos docentes e acadêmicos do Curso de Pedagogia da UFMS (trabalho desenvolvido nas disciplinas de Ludicidade e Educação e de Fundamentos $e$ Metodologias da Educação Infantil - isso tendo ocorrido no mês de junho de 2019); iii) nessa etapa será realizada a segunda palestra (mês de agosto) com a participação de todos os inscritos no projeto; iv) na quarta etapa, no mês de setembro de 2019, serão oferecidas duas oficinas simultâneas, de estudo e de confecção de jogos, brinquedos e brincadeiras para as crianças de 0 a 5 anos; v) na quinta etapa haverá a última palestra e uma exposição dos materiais das oficinas (confeccionados pelos professores da educação infantil) para os demais acadêmicos de Pedagogia da UFMS-CPNV; vi) a sexta etapa compreenderá a avaliação geral, em que serão tabulados os dados das avaliações de cada etapa, incluindo a preparação de um relatório final em outubro/novembro de 2019.

Em cada etapa do projeto serão realizadas avaliações periódicas. Assim, a avaliação das discussões teóricas e das oficinas com acadêmicos serão realizadas em sala de aula, por meio de questionário com questões abertas, de periodicidade única. Por sua vez, a avaliação das exposições de jogos, brinquedos e brincadeiras será realizada pelos visitantes e pelos organizadores em breve formulário (periodicidade única). 
A avaliação das palestras e das oficinas com os professores da educação infantil será realizada em formulário próprio (com periodicidade única) a ser preenchido pelos professores da educação infantil, pelos acadêmicos e pelos integrantes da equipe de organização do projeto. A exposição realizada pelos cursistas do projeto será avaliada pelos visitantes em formulário próprio. Dessa maneira, a avaliação final será realizada pela equipe do projeto por meio da tabulação dos indicadores e da verificação do alcance dos objetivos propostos no projeto.

\section{CONSIDERAÇÕES FINAIS}

Estabelecemos alguns indicadores para avaliar o projeto de extensão. São eles: i) compreensão da importância do brincar como ferramenta para o desenvolvimento infantil e parte integrante do currículo da educação infantil; ii) identificação e análise de materiais lúdicos para a compreensão do uso no currículo da educação infantil; e iii) produção e exposição de materiais lúdicos compreendendo a relação deles com as faixas etárias da educação infantil.

Tendo em vista que o projeto iniciou suas atividades em junho de 2019 e se encontra em andamento, a avaliação dos indicadores ainda é prematura, mas podemos afirmar que a primeira etapa, que foi desenvolvida por meio de uma palestra e visitação à "Feira de Jogos, Brinquedos e Brincadeiras" da UFMS/Campus de Naviraí foi considerada uma atividade importante para a compreensão do brincar no contexto da educação da infância.

A primeira palestra, ministrada no mês de junho, teve como tema "A criança como protagonista do brincar em suas infâncias e singularidades" e tratou da conceptualização de jogo, de brinquedo e de brincadeira segundo diversos autores e ressaltou a relevância de se repensar os espaços, os materiais e a organização do brincar nas instituições de educação infantil.

Com base nos estudos da pesquisadora Kishimoto (2011) sobre as instituições de educação infantil no Brasil, foi destacado como muitas vezes as instituições de educação infantil públicas, desde a década de 1970, incorporaram um brincar "livre" com as crianças, no entanto, sem a organização de espaços e materiais, ou quase sempre com uma ausência de materiais lúdicos para as crianças das camadas populares. Posto isto, há necessidade premente de se rever a formação docente inicial e continuada de professores da educação infantil no que se refere ao lúdico, de forma a incorporar as contribuições culturais e experienciais da infância na produção e/ou incorporação dos jogos/brinquedos/brincadeiras.

Não menos importante é a revisão das propostas pedagógicas das instituições de educação infantil, pois incorporar o lúdico como eixo fundamental do trabalho com as crianças é primordial e urgente, em razão de que a tarefa de educação e cuidado é permeada, durante todo o processo de desenvolvimento infantil, pelo aspecto lúdico.

\section{REFERÊNCIAS}

BERNARDES, E. L. Jogos e brincadeiras: ontem e hoje. Cadernos de História da Educação, no 4, jan./dez. 2005. Disponível em: <http://www.seer.ufu.br/index.php/ che/article/view/384>. Acesso em: 20 jan. 2019. 
BORBA, A. M. O brincar como modo de ser e estar no mundo. In: BRASIL. Ministério da Educação. Ensino fundamental de nove anos: orientações para a inclusão da criança de seis anos de idade. Brasília, DF: FNDE/Estação Gráfica, 2007.

BRASIL. Ministério da Educação. Secretaria de Educação Básica. Diretrizes Curriculares Nacionais para a Educação Infantil. Brasília, DF: MEC/SEB, 2010.

KISHIMOTO, T. M. Salas de aulas nas escolas infantis e o uso de brinquedos e materiais pedagógicos. In: 23a REUNIÃO DA ANPED, 24 a 28 de setembro de 2000, Caxambu/MG. Anais... Caxambu, MG, 24 a 28 de setembro de 2000. Disponível em: <http://23reuniao.an ped.org.br>. Acesso em: 20 jan. 2019.

Brinquedos e brincadeiras na educação infantil. In: SEMINÁRIO NACIONAL: CURRÍCULO EM MOVIMENTO, Perspectivas Atuais, 2010, Belo Horizonte, MG. Anais... Belo Horizonte, novembro de 2010, p. 1-20. Disponível em: <http://portal.mec. gov.br/index.php?option=com_docman\&view=download\&alias=7155-2-3-brinquedosbrinca deiras-tizuko-morchida\&category_slug=dezembro-2010-pdf\&Itemid=30192>. Acesso em: 20 jan. 2019.

brinquedo e brincadeira - usos e significações dentro de contextos culturais. In: SANTOS, S. M. P. (Org.). Brinquedoteca - o lúdico em diferentes contextos. 14. ed. Petrópolis, RJ: Vozes, 2011.

O jogo e a educação infantil. In: KISHIMOTO, T. M. (Org.). Jogo, brinquedo, brincadeira e a educação. 14. ed. São Paulo, SP: Cortez, 2011.

. (Org.). Jogo, brinquedo, brincadeira e a educação. 14 ed. São Paulo, SP:

Cortez, 2011.

RIBEIRO, P. S. Jogos e brinquedos tradicionais. In: SANTOS, S. M. P. dos (Org.). Brinquedoteca - o lúdico em diferentes contextos. 14. ed. Petrópolis, RJ: Vozes, 2011.

SANTOS, S. M. P. dos (Org.). Brinquedoteca - o lúdico em diferentes contextos. 14. ed. Petrópolis, RJ: Vozes, 2011.

WAJSKOP, G. O brincar na educação infantil. Cadernos de Pesquisa, São Paulo/SP, n. 92, p. 62-69, fev. 1995.

Recebido em: 03/05/2019

Aprovado em: 005/07/2019 